\title{
Pregnancy augments hepatic glucose storage in response to a mixed meal
}

\author{
Mary Courtney Moore*, Marta S. Smith and Cynthia C. Connolly† \\ Department of Molecular Physiology \& Biophysics, Vanderbilt University School of Medicine, 702 Light Hall, Nashville, \\ TN 37232-0615, USA
}

(Received 3 February 2011 - Revised 5 May 2011 - Accepted 9 May 2011 - First published online 11 August 2011)

\section{Abstract}

Studies were carried out on conscious female non-pregnant (NP) and pregnant (P; third-trimester) dogs ( $n$ 16; eight animals per group) to define the role of the liver in mixed meal disposition with arteriovenous difference and tracer techniques. Hepatic and hindlimb substrate disposal was assessed for $390 \mathrm{~min}$ during and after an intragastric mixed meal infusion labelled with $\left[{ }^{14} \mathrm{C}\right] \mathrm{glucose}$. The P dogs exhibited postprandial hyperglycaemia compared with NP dogs (area under the curve (AUC; change from basal over $390 \mathrm{~min}$ ) of arterial plasma glucose: 86680 (SEM 12 140) and 187990 (SEM 33990) mg/l in NP and P dogs, respectively; $P<0 \cdot 05$ ). Plasma insulin concentrations did not differ significantly between the groups (AUC: 88230 (SEM 16314) and 69750 (SEM 19512) pmol/1 in NP and P dogs, respectively). Net hepatic glucose uptake totalled 3691 (SEm 508) v. 5081 (SEm 1145) mg/100g liver in NP and $\mathrm{P}$ dogs, respectively $(P=0.38$ ). The AUC of glucose oxidation by the gut and hindlimb were not different in NP and P dogs, but hepatic glucose oxidation (84 (SEM 13) v. 206 (SEM 30) $\mathrm{mg} / 100 \mathrm{~g}$ liver) and glycogen synthesis $(0.4$ (SEM 0.5$) v .26$ (SEM 0.7$) \mathrm{g} / 100 \mathrm{~g}$ liver) were greater in $\mathrm{P}$ dogs $(P<0.05)$. The proportion of hepatic glycogen deposited via the direct pathway did not differ between the groups. Hindlimb glucose uptake and skeletal muscle glycogen synthesis was similar between the groups, although final glycogen concentrations were higher in NP dogs ( 9.6 (SEM 0.6) v. $70($ SEM 0.6$) \mathrm{mg} / \mathrm{g}$ muscle; $P<0.05$ ). Thus, hepatic glucose oxidation and glycogen storage were augmented in late pregnancy. Enhanced hepatic glycogen storage following a meal probably facilitates the maintenance of an adequate glucose supply to maternal and fetal tissues during the post-absorptive period.

\section{Key words: Pregnancy: Glucose: Metabolism}

Normal pregnancy is associated with insulin resistance and altered glucose tolerance that has been well characterised in human subjects and animal models ${ }^{(1-3)}$. While the peripheral tissues (especially muscle) exhibit a $\geq 50 \%$ decrease in insulin sensitivity by late pregnancy ${ }^{(4-6)}$, hepatic glucose production (HGP) continues to be suppressed by hyperinsulinaemia ${ }^{(5,6)}$. Oral glucose tolerance tests are widely used during pregnancy for the diagnosis of impaired glucose tolerance and gestational diabetes. Mixed meal tolerance tests have been suggested as a more informative and physiological alternative to glucose tolerance tests, since they provide data about metabolism of all macronutrients, not just carbohydrate, and they stimulate the release of glucagon, in addition to insulin and incretin hormones ${ }^{(7-9)}$. The metabolic response to a mixed meal, and particularly the role of the liver in the disposition of a mixed meal, has been less well studied than disposition of a glucose load during pregnancy, however.

The conscious dog model is near-unique in its ability to allow assessment of hepatic glucose uptake (HGU), because its size allows cannulation of the vessels supplying and draining the liver. These cannulations are too invasive to be employed in humans, and no reports of measurement of HGU in rodents have been published, underscoring the difficulty of transferring the technique to small animal models. Therefore, we used the conscious dog to assess the roles of the liver and peripheral tissues in the disposition of a standardised mixed meal, particularly in regard to the uptake of glucose and synthesis of glycogen. Quantifying the disposition of a mixed meal provides a better understanding of the way the body meets both the fetal and maternal nutrient requirements during late pregnancy.

\footnotetext{
Abbreviations: AAALAC, Association for the Assessment and Accreditation of Laboratory Animal Care; AUC, area under the curve; HGP, hepatic glucose production; HGU, hepatic glucose uptake; HL, hepatic load; NGGO, net gut glucose output; NHGU, net hepatic glucose uptake; NP, non-pregnant; $\mathrm{P}$, pregnant.
}

*Corresponding author: M. C. Moore, fax +1 615343 0490, email genie.moore@vanderbilt.edu

†Deceased. 


\section{Methods}

\section{Animals and surgical procedures}

Studies were conducted on normal conscious female non-pregnant (NP) and pregnant (P) mongrel dogs ( $n$ 16; eight animals per group). Vanderbilt University (Nashville, TN, USA) has a comprehensive animal care and use programme that is registered with the United States Department of Agriculture and fully accredited by the Association for the Assessment and Accreditation of Laboratory Animal Care, International (AAALAC-International). The protocol was approved by the Vanderbilt University Institutional Animal Care and Use Committee before initiation of the studies, and all institutional, federal and AAALAC guidelines were adhered to in conducting these studies. The P dogs were studied in the 7th-8th week of gestation (total duration of pregnancy approximately 9 weeks). The NP dogs had basal oestrogen and progesterone concentrations. Body weights at the time of experimentation were 23.7 (SEM 1.2) and $26 \cdot 3($ SEM 1.0$) \mathrm{kg}$ for NP and P dogs, respectively $(P=0 \cdot 10)$. Before the day of the study, all dogs were fed once daily a diet of meat (Pedigree; Mars PetCare, Franklin, TN, USA) and chow (Purina Lab Canine Diet no. 5006; PMI Nutrition, Henderson, CO, USA) with a combined composition of $34 \%$ protein, $14.5 \%$ fat, $46 \%$ carbohydrate and $5.5 \%$ fibre based on dry weight. The diet was nutritionally adequate for $\mathrm{P}$ dogs, and the animals in both groups consumed approximately $6908-7745 \mathrm{~kJ} /$ d (1650-1850 kcal/d). Approximately $16 \mathrm{~d}$ before the experiment, each dog underwent a laparotomy under general anaesthesia (isoflurane, $0.8 \%$ ). Sampling catheters were placed in the femoral artery, portal vein, left common hepatic vein and right common iliac vein; ultrasonic flow cuffs (Transonic Systems, Ithaca, NY, USA) were positioned about the hepatic artery, portal vein and external iliac artery; and a gastrostomy tube was inserted as described previously ${ }^{(10,11)}$. The distal ends of the catheters and flow probes were placed in subcutaneous pockets. Criteria for use of an animal for experimentation were as described previously ${ }^{(12)}$.

\section{Experimental procedures}

All dogs were fasted for $18 \mathrm{~h}$ before the experiment. On the morning of the experiment, a primed $(36 \mu \mathrm{Ci})$, continuous $(0 \cdot 3 \mu \mathrm{Ci} / \mathrm{min})$ infusion of $\left[3-{ }^{3} \mathrm{H}\right]$ glucose was begun via a cephalic vein. The experiment consisted of a 90 min equilibration period ( -120 to $-30 \mathrm{~min}$ ), a $30 \mathrm{~min}$ basal period $(-30$ to $0 \mathrm{~min})$, a $30 \mathrm{~min}$ period $(0-30 \mathrm{~min})$ of continuous intragastric infusion of a liquid-defined formula diet and then a $360 \mathrm{~min}$ postprandial period (30-390 min). The meal consisted of $38 \%$ protein, $17 \%$ fat and $45 \%$ carbohydrate, in the form of whey protein (ProMod; Abbott Nutrition, Columbus, OH, USA), lipid emulsion (Microlipid; Nestlé, Minneapolis, MN, USA) and D-glucose (Sigma, St Louis, MO, USA); the macronutrient contributions to total energy intake were designed to be as close as possible to the animals' usual diet. Each animal received $2.8 \mathrm{~g}$ protein $/ \mathrm{kg}, 0.6 \mathrm{~g} \mathrm{lipid} / \mathrm{kg}$ and $3.2 \mathrm{~g}$ glucose $/ \mathrm{kg}$, and $250 \mu \mathrm{Ci}\left[\mathrm{U}-{ }^{14} \mathrm{C}\right.$ ]glucose was added to the formula infused.
Blood was drawn every 15 min during the basal and early postprandial periods, with the sampling interval being increased later in the postprandial period. At the end of the study, each animal was killed with an overdose of pentobarbital. A biopsy from each of the seven maternal liver lobes and three skeletal muscles (sartorius, gracilis and gastrocnemius) was immediately freeze-clamped in liquid $\mathrm{N}_{2}$ and stored at $-80^{\circ} \mathrm{C}$ for future analysis of glycogen content.

\section{Sample analysis}

Samples were analysed for haematocrit, plasma glucose, NEFA, insulin, glucagon, $\left[{ }^{3} \mathrm{H}\right]$ glucose and $\left[{ }^{14} \mathrm{C}\right]$ glucose-specific activities, and blood glucose, lactate, alanine, glycerol, $\beta$-hydroxybutyrate, acetoacetate and gluconeogenic amino acids as described previously ${ }^{(12,13)}$. ${ }^{14} \mathrm{CO}_{2}$ measurements were performed in triplicate on arterial, portal vein and hepatic vein blood ${ }^{(10)} \cdot{ }^{14} \mathrm{C}$-labelled glucose, lactate and alanine were separated by ion-exchange chromatography ${ }^{(10,14)}$. Glycogen content of liver and muscle was analysed enzymatically following acid precipitation ${ }^{(15)}$.

\section{Calculations}

Arterial, portal and hepatic vein substrate concentrations were used for calculation of organ balance by the arteriovenous difference technique. The rate of substrate delivery to the liver (hepatic load; HL) was calculated as follows: $\mathrm{HL}=A \times$ $Q_{\mathrm{A}}+P \times Q_{\mathrm{P}}$, where $A$ and $P$ are the blood or plasma concentrations of the substrate in the femoral artery and portal vein, respectively, and $Q_{\mathrm{A}}$ and $Q_{\mathrm{P}}$ are the rates of blood or plasma (as appropriate) flow through the hepatic artery and portal vein, respectively. Plasma flow was derived from blood flow; plasma flow $=$ blood flow $\times(1-$ haematocrit $)$. Net hepatic balances (NHB) of substrates were calculated with the following formula: $\mathrm{NHB}=H \times Q_{\mathrm{H}}-\mathrm{HL}$, where $H$ is the hepatic vein substrate concentration (blood or plasma) and $Q_{\mathrm{H}}$ is the total hepatic blood or plasma flow (i.e. $Q_{\mathrm{A}}+Q_{\mathrm{P}}$ ). Net fractional substrate extraction by the liver was the ratio of NHB:HL. Net gut balance was calculated as follows: net gut balance $=$ $(P-A) \times Q_{\mathrm{P}}$. Plasma glucose values were converted to blood values as described previously ${ }^{(13)}$. Net gut and hepatic balances of $\left[{ }^{14} \mathrm{C}\right]$ glucose and ${ }^{14} \mathrm{CO}_{2}$ (in disintegrations per $\mathrm{min}(\mathrm{dpm}) / \mathrm{kg}$ per min) were calculated as for other substrates, but using plasma flows. The results were divided by the inflowing glucose specific radioactivity $(\mathrm{dpm} / \mathrm{mg}$ glucose) to convert them to glucose; the specific activity of glucose in the meal was used for net gut uptake and oxidation, and the weighted specific activity of glucose in the artery and portal vein was used for net hepatic uptake and oxidation. The HL and balance data for substrates are expressed per $100 \mathrm{~g}$ liver weight, to correct for differences in body size between the groups. However, the data were also calculated per kg body weight, and the conclusions did not differ. Maternal liver weights at the end of the study were 715 (SEM 43) and 836 (SEM 72) $\mathrm{g}$ in the NP and $\mathrm{P}$ groups, respectively $(P=0 \cdot 14)$.

Hepatic glycogen synthesis (cold) was calculated as the difference between the final glycogen concentrations in the 
mixed meal-fed animals and the concentrations in liver biopsies taken from $18 \mathrm{~h}$-fasted NP $(n$ 5) and $\mathrm{P}$ (thirdtrimester; $n$ 4) dogs. Net deposition of glycogen in liver was also calculated using both $\left[{ }^{3} \mathrm{H}\right]$ glucose and $\left[{ }^{14} \mathrm{C}\right]$ glucose by dividing hepatic tracer glycogen accumulation ( $\mathrm{dpm} / \mathrm{g}$ liver) by the average inflowing tracer glucose specific activities. Indirect glycogen synthesis was determined by the difference between ${ }^{14} \mathrm{C}$ - and ${ }^{3} \mathrm{H}$-determined glycogen synthesis.

The hindlimb of the dog is approximately $66 \%$ muscle, with most of the remainder of the mass being bone, and therefore it served as an index of muscle glucose uptake ${ }^{(11)}$. Hindlimb balance $=(A-I) \times Q_{\mathrm{I}}$, where $I$ and $Q_{\mathrm{I}}$ indicate the iliac vein substrate concentration and iliac artery blood flow, respectively. Hindlimb fractional extraction was calculated as hindlimb balance divided by load to the limb $\left(A \times Q_{\mathrm{I}}\right)$.

The trapezoidal rule was used to calculate the area under the curve (AUC) for the $390 \mathrm{~min}$ prandial and postprandial periods. Only positive excursions from zero (i.e. net gut production of substrates) were used in the calculation of AUC for gut disposition of glucose. Both positive and negative excursions (i.e. net balance) were included in the calculations of hepatic and hindlimb disposition of substrates.

Repeated-measures ANOVA was used for statistical comparisons of time-course data, with the Tukey test for post hoc analysis (Systat, Chicago, IL, USA). For comparison of single items of data (e.g. AUC or glycogen concentrations between the groups), $t$ tests were used unless the data failed the test of normality, in which case Mann-Whitney rank sum tests were used (as indicated later).

\section{Results}

\section{Hormone concentrations}

Arterial plasma insulin concentrations tended to be higher in $\mathrm{NP} v$. $\mathrm{P}$ dogs both in the basal period and following the meal, but this did not reach statistical significance $(P=0 \cdot 21$ for the time-course data; Fig. 1). The peak postprandial concentrations in NP dogs (438 (SEM 78) pmol/l) were obtained 15 min after the end of the meal, but the peak in the P animals (336 (SEM 84) pmol/l) was not evident until 60 min postprandially ( $P=0.34$ for peak concentrations). The timing of the peak was highly variable within both groups. The AUC of the insulin response (change from basal concentrations) was 88230 (SEM 16314) and 69750 (SEM 19512) pmol/l per $390 \mathrm{~min}$ in NP and $\mathrm{P}$ dogs, respectively $(P=0 \cdot 23)$. The glucagon and cortisol concentrations did not differ between the groups at any time (Fig. 1).

\section{Glucose concentrations and balance data}

Arterial plasma glucose concentrations did not differ between the groups in the basal period, but the postprandial concentrations between 60 and 210 min were significantly higher in the P group (Fig. 2), and the AUC of the change from basal concentrations was 2-fold higher in the $\mathrm{P}$ group (187990 (SEM 33590) v. 86680 (SEM 12140) $\mathrm{mg} / \mathrm{l}$ per $390 \mathrm{~min}$, $P<0.05$ ). Portal vein plasma glucose was significantly higher

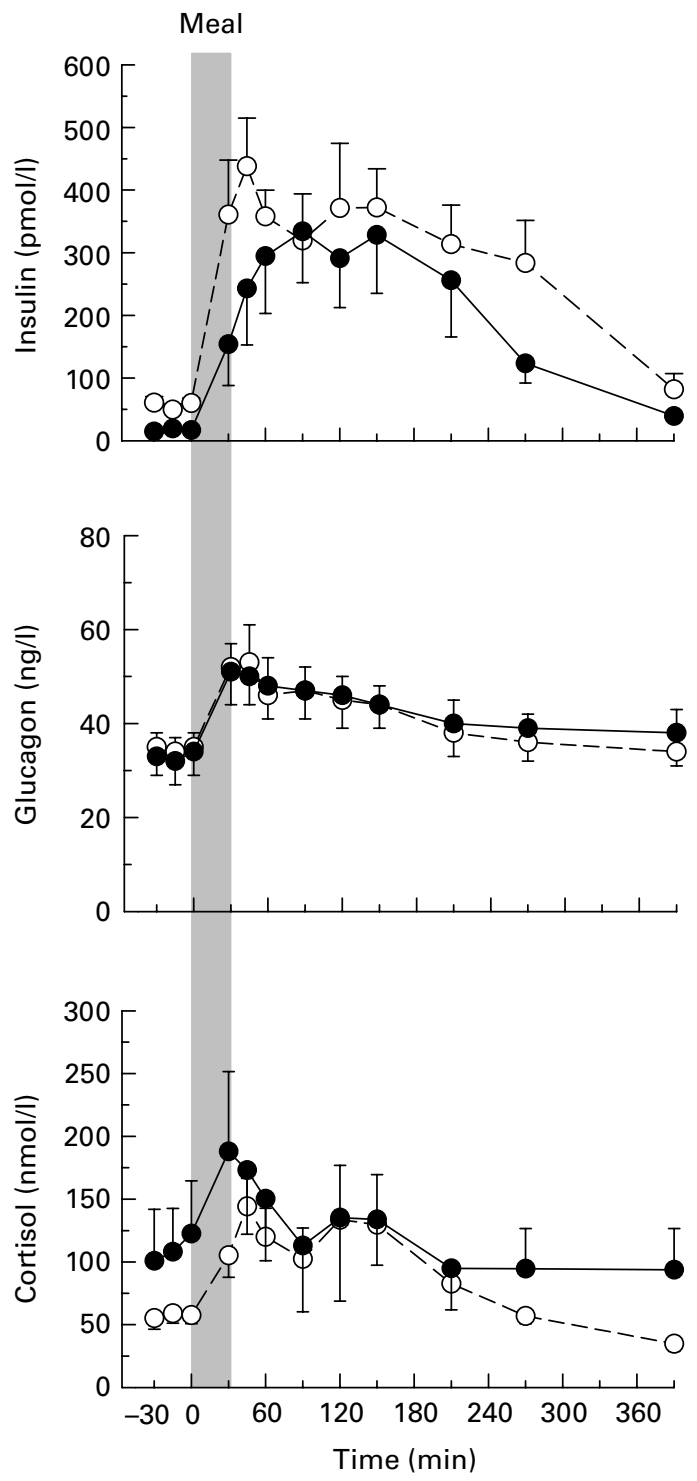

Fig. 1. Arterial plasma concentrations of insulin, glucagon and cortisol in non-pregnant (NP; - $\mathrm{O}_{-}$) and pregnant $\left(\mathrm{P} ;-\bullet_{-}\right)$dogs. Values are means, with their standard errors represented by vertical bars ( $n 8$ per group). The grey bar indicates the period of continuous intragastric meal infusion. Mean values were not significantly different between the groups.

in the $\mathrm{P} v$. NP group from 90 to $390 \mathrm{~min}$ (AUC 198910 (SEM 14510) v. 302850 (SEM 45400) $\mathrm{mg} / \mathrm{l}$ per $390 \mathrm{~min}, P<0 \cdot 05$ ). Hepatic blood flow (Table 1) tended to be lower in the $\mathrm{P}$ group, although neither hepatic artery $(P=0 \cdot 31)$ nor portal vein $(P=0 \cdot 27)$ blood flow differed significantly between the groups. Both groups demonstrated a significant postprandial rise in portal vein flow. The hepatic glucose load did not differ significantly between the groups (Fig. 2).

During the basal period, both groups exhibited net gut glucose uptake, which shifted to net gut glucose output (NGGO) concomitantly with feeding. Overall, NGGO was not significantly different between the groups (Fig. 2), and the AUC totalled $68.2(\operatorname{SEm} 3.2)$ and $61.9(\operatorname{SEM} 7.4) \%$ of the administered glucose in the NP and $\mathrm{P}$ groups, respectively $(P=0.52)$. 

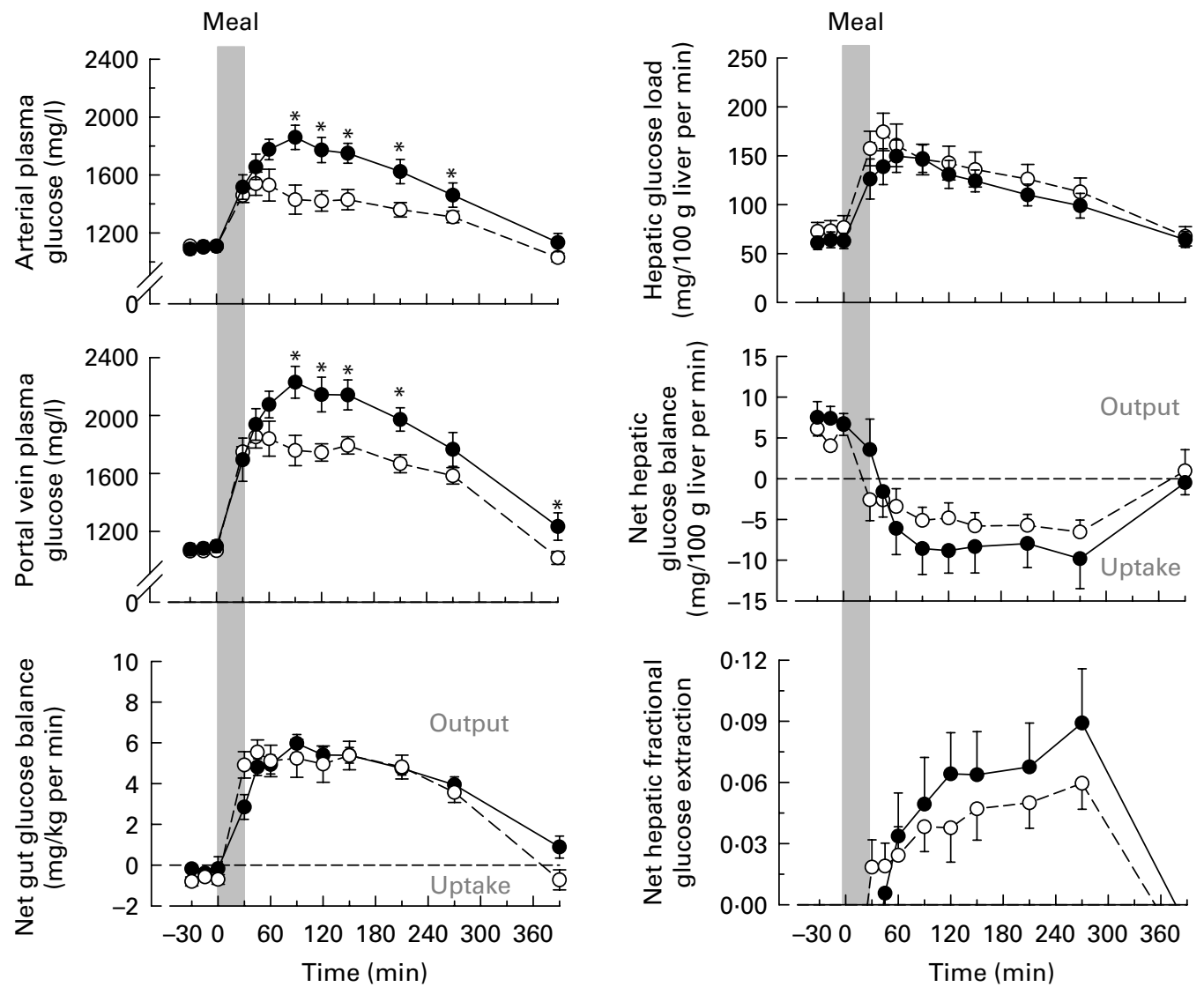

Fig. 2. Arterial and portal vein plasma glucose concentrations, net gut glucose output, hepatic glucose load, net hepatic glucose uptake and net hepatic fractional glucose extraction in non-pregnant (NP; $\left.-\mathrm{O}_{-}\right)$and pregnant $\left(\mathrm{P} ;-\mathbf{-}_{-}\right)$dogs. Values are means, with their standard errors represented by vertical bars $(n 8$ per group). The grey bar indicates the period of continuous intragastric meal infusion. * Mean values were significantly different between the groups $(P<0 \cdot 05$; post hoc analysis).

The peak rate of NGGO occurred at $45 \mathrm{~min}$ in the NP group compared with $90 \mathrm{~min}$ in the $\mathrm{P}$ group. By $390 \mathrm{~min}$, the NP group had returned to basal rates of net gut glucose uptake, but the $\mathrm{P}$ group continued to display NGGO. If net gut glucose balance in the two groups was compared only at the 390 time point, using the Mann-Whitney test, the rates would have been significantly different $(-0.7$ (SEM 0.5$) v .0 .9($ SEM 0.5$) \mathrm{mg} / \mathrm{kg}$ per min in NP $v$. P dogs, respectively; $P<0.05)$. The AUC of gut glucose oxidation was similar in the two groups (11 (SEM 5) and $12(\operatorname{sem~} 11) \mathrm{mg} / \mathrm{kg}$ per $390 \mathrm{~min}(P=0.99)$, or a total of 220 (sEM 97) and 306 (SEM 295) $\mathrm{mg} / 390 \mathrm{~min}(P=0 \cdot 78)$, in NP and P dogs, respectively; Fig. 3).

The rates of net hepatic glucose output during the basal period were not significantly different between the groups, and both groups shifted to net hepatic glucose uptake (NHGU) during the postprandial period, although the shift appeared to be slightly slower in the $\mathrm{P}$ group (Fig. 2). The AUC of NHGU (calculated as change from basal rates) were 3691 (SEM 475) and 5304 (SEM 1105) $\mathrm{mg} / 100 \mathrm{~g}$ liver $390 \mathrm{~min}$ in NP and $\mathrm{P}$ dogs, respectively $(P=0.38)$. If expressed per kg body weight, NHGU would have totalled 1108 (SEM 135) and 1562 (SEM 296) $\mathrm{mg} / \mathrm{kg}$ per $390 \mathrm{~min}$ in NP and P dogs, respectively $(P=0 \cdot 16)$. HGU calculated with $\left[{ }^{14} \mathrm{C}\right]$ glucose totalled 2723 (SEM 1230) and 4471 (SEM 1450) mg/100g liver per $390 \mathrm{~min}$ in $\mathrm{NP}$ and $\mathrm{P}$ dogs, respectively $(P=0.34)$.
Hepatic glucose oxidation was higher in the $\mathrm{P}$ group than in the NP group during the early postprandial period $(P<0.05$; Fig. 3), although oxidation was a minor fate in the liver and the other organs and tissues examined. The AUC of hepatic fractional glucose extraction was approximately $40 \%$ greater in the $\mathrm{P}$ group $(P=0 \cdot 13$; Fig. 2$)$.

Hindlimb blood flow was not significantly different between the groups $(P=0 \cdot 39$; Table 1$)$. In addition, hindlimb glucose uptake (Fig. 4) and glucose oxidation (Fig. 3) did not differ significantly between the groups. The AUC of hindlimb fractional glucose extraction was nearly 10 -fold higher in the NP group than in the $\mathrm{P}$ group, however (Fig. $4 ; P<0.05$ ).

\section{Non-glucose substrates}

Lactate concentrations and balance data did not differ significantly between the groups at any time (Table 2). In the early postprandial period, there was a surge of net hepatic lactate output in both groups, with a consequent rise in arterial lactate concentrations. The AUC of net hepatic lactate output was $50 \%$ greater in the NP group than in the $\mathrm{P}$ group $(P=0.07)$. Hindlimb lactate uptake increased in parallel with the increase in circulating concentrations.

Basal arterial blood glycerol concentrations tended to be higher $(P=0 \cdot 15)$ in the $\mathrm{P} v$. NP group. The concentrations 
and net hepatic glycerol uptakes in both groups fell during the early postprandial period and then returned to basal by the end of the study (Table 2). Hindlimb glycerol uptake was significantly lower in the $\mathrm{P} v$. NP group during the basal period, but the rate declined similarly in both groups in the postprandial period. Arterial NEFA concentrations were significantly higher in the $\mathrm{P} v$. NP group during the basal and early postprandial period. The NEFA concentrations and net hepatic uptake rates fell in both groups in the postprandial period (Table 2), and the concentrations and net hepatic output of $\beta$-hydroxybutyrate declined as well. $\beta$-Hydroxybutyrate and acetoacetate concentrations and balance data did not differ between the groups (see Table S1 of the supplementary material, available online at http://www.journals.cambridge. org/bjn).

Arterial concentrations of alanine and net hepatic uptake of alanine were significantly lower in the $\mathrm{P} v$. NP group during the basal period (Table 2). With the exception of glycine, the arterial concentrations and net hepatic and hindlimb uptakes of the other gluconeogenic amino acids increased similarly in the postprandial period (see Table S2 of the supplementary material, available online at http://www.journals. cambridge.org/bjn). In the $\mathrm{P}$ group, arterial glycine concentrations increased postprandially while there was no increase in the NP group, resulting in a significant difference in concentrations during 30-210 min.

\section{Muscle and hepatic glycogen}

The glycogen concentrations of the three skeletal muscles were very homogeneous, and therefore the values were averaged for each dog. The muscle glycogen concentrations at the end of the study were $37 \%$ higher in NP $v$. P dogs, although the rates of muscle glycogen synthesis did not differ significantly (Table 3).

Hepatic glycogen concentrations in the dogs from which biopsies were taken after an $18 \mathrm{~h}$ fast averaged 4.9 (SEM 0.5) and 3.6 (sem 0.9) $\mathrm{mg} / 100 \mathrm{~g}$ liver in NP and P dogs, respectively $(P=0 \cdot 07)$. Because the livers of $\mathrm{P}$ dogs were larger $(P<0 \cdot 01)$ than those of NP dogs, the total hepatic glycogen content was virtually identical in NP and $\mathrm{P}$ dogs after the $18 \mathrm{~h}$ fast (24.8 (SEM 3.0) and 23.9 (SEM 7.6) g, respectively). In the meal-fed animals, hepatic glycogen concentrations at the end of the study tended to be greater in the $\mathrm{P} v$. NP group $(P=0.14$ or 0.07 , depending on whether the data are expressed in $\mathrm{mg} / \mathrm{g}$ liver or $\mathrm{g}$ /liver; Table 3). Postprandial net hepatic glycogen synthesis was 6- to 7-fold greater in the $\mathrm{P}$ $v$. NP group, but the percentage contribution of the direct pathway did not differ between the groups $(P=0 \cdot 80)$.

\section{Discussion}

The $\mathrm{P}$ dogs exhibited marked postprandial hyperglycaemia. We previously observed an increased AUC of plasma glucose concentrations in normal $\mathrm{P} v$. NP female dogs following an oral glucose $\operatorname{load}^{(16)}$, which is consistent with the present results. Glucose absorption appeared to be prolonged in $\mathrm{P} v$. NP dogs, which might have resulted from reduced gut 

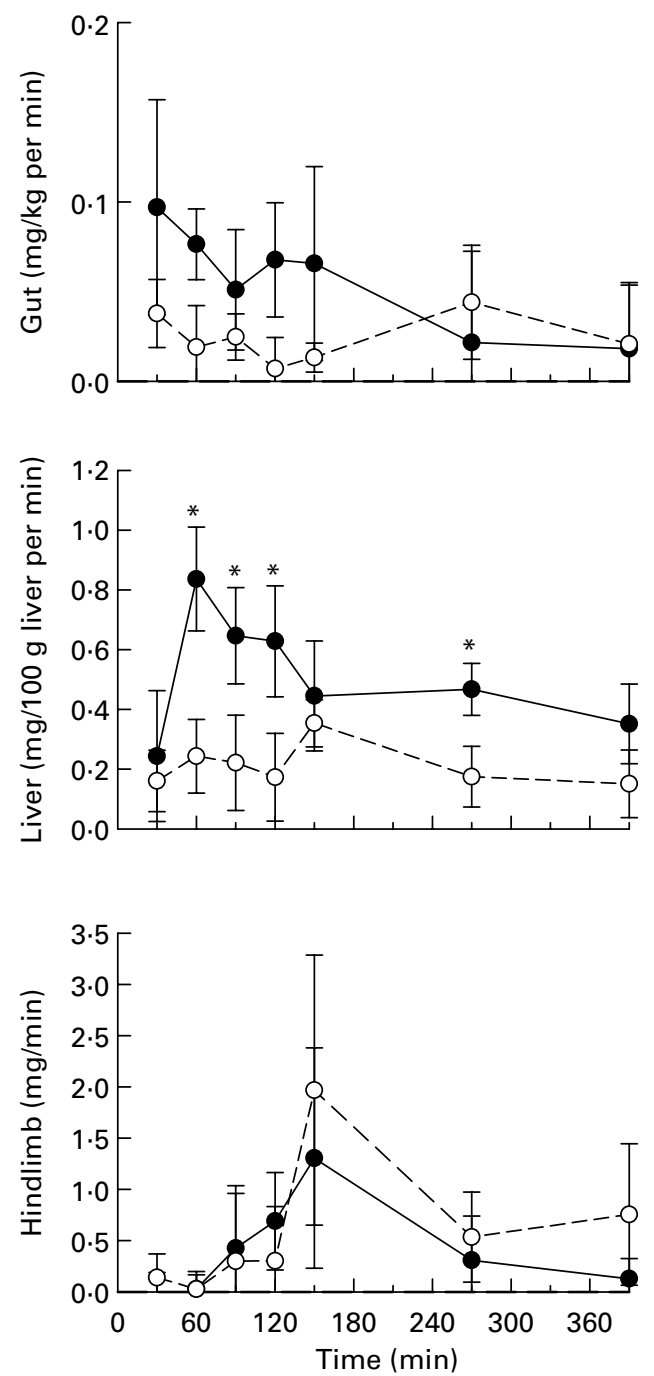

Fig. 3. Postprandial glucose oxidation by the gastrointestinal tract, liver

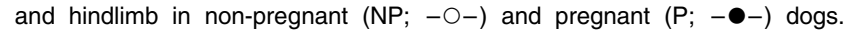
Values are means, with their standard errors represented by vertical bars ( $n 8$ per group). * Mean values were significantly different between the groups $(P<0.05)$.

motility as a consequence of elevated progesterone in the $\mathrm{P}$ animals ${ }^{(17)}$ or a delay in gastric emptying related to the hyperglycaemia in the $\mathrm{P}$ group ${ }^{(18,19)}$. The hepatic glucose loads (a determinant of the rate of $\mathrm{NHGU}^{(20)}$ ) in the two groups were virtually identical throughout the postprandial period, despite the postprandial hyperglycaemia in $\mathrm{P}$ dogs. This occurred because hepatic blood flow tended to be lower in $\mathrm{P} v$. NP dogs, which is consistent with our previous findings ${ }^{(5)}$. The rate of NHGU (the sum of two processes, HGP and HGU) under postprandial conditions has not been assessed previously in human subjects during pregnancy because it is not possible to cannulate the portal vein. Likewise, to our knowledge, there is only one previous report quantifying NHGU during pregnancy in a non-ruminant animal model, an assessment of the response to meal feeding in $\mathrm{P}$ rabbits ${ }^{(21)}$. However, in rabbits, unlike human subjects and $\operatorname{dogs}{ }^{(1,5)}$, the liver exhibits insulin resistance during normal pregnancy ${ }^{(22)}$. This might be related to the fact that NEFA concentrations are markedly elevated in $\mathrm{P} v$. NP rabbits after an overnight fast ${ }^{(21)}$. While NEFA concentrations tend to be moderately elevated in normal overnight-fasted $\mathrm{P} v$. NP women and dogs, the magnitude of the increase is much less than in $\mathrm{P}$ rabbits (approximately 1.0- to $1 \cdot 3$-fold in women $^{(23-25)}$ and $\operatorname{dogs}{ }^{(12,26)} v \cdot 1 \cdot 8$-fold in rabbits $\left.{ }^{(21)}\right)$. Although it has been suggested that circulating NEFA levels are poorly correlated with the suppressibility of endogenous glucose production in pregnancy ${ }^{(27)}$, NEFA concentrations are a key determinant of endogenous glucose production in the NP state $^{(28)}$. HGP in normal P women and dogs is known to be suppressible by insulin under euglycaemic conditions to a similar extent as in NP controls ${ }^{(1,5)}$, and the current data indicate that postprandial HGU is at least as great during late pregnancy as in NP females, in the presence of similar changes in insulin concentrations. In our previous findings in NP and P dogs studied under clamp conditions with matched levels of hyperinsulinaemia and hyperglycaemia in the presence of portal vein glucose infusion, the AUC of NHGU was significantly reduced in the P group $^{(29)}$. This suggests that hyperglycaemia following the mixed meal feeding allowed the $\mathrm{P}$ group to achieve normal or even enhanced rates of hepatic glucose disposal.

Cardiac output increases in pregnancy in the $\operatorname{dog}^{(30)}$, as in other species, and thus it might seem surprising that hepatic

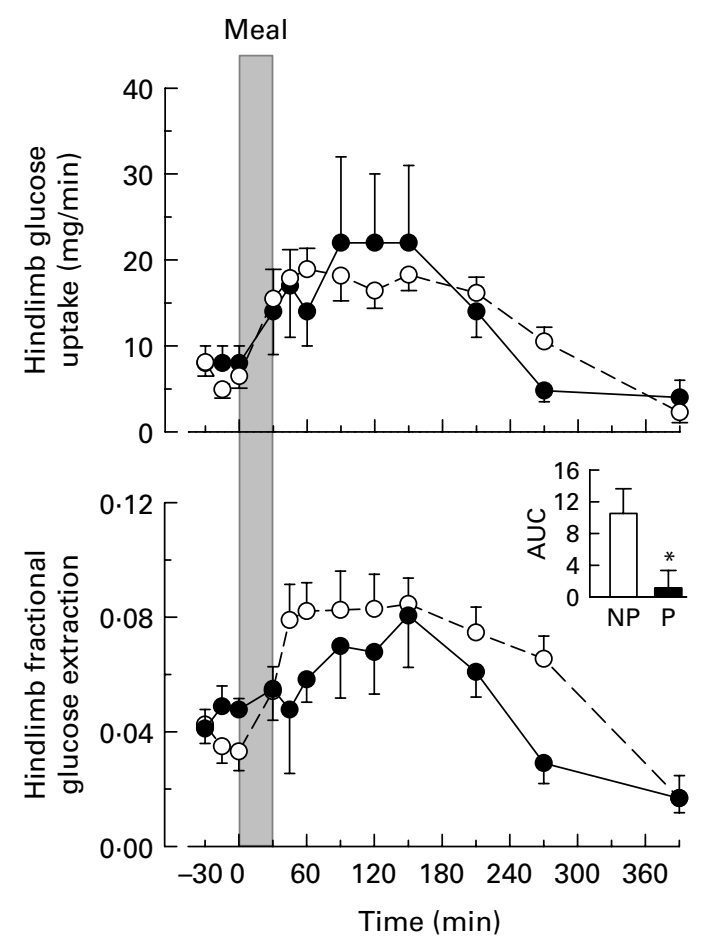

Fig. 4. Hindlimb glucose uptake and fractional extraction in non-pregnant (NP; - - - - ) and pregnant $(\mathrm{P} ; \longrightarrow-$ ) dogs. Values are means, with their standard errors represented by vertical bars ( $n 8$ per group). The grey bar indicates the period of continuous intragastric meal infusion. The inset histogram shows the area under the curve (AUC) of change from basal in fractional extraction (NP, $\square ; P, \boldsymbol{Q})$. * Mean values were significantly different from those of the NP group $(P<0.05)$. 
Table 2. Concentrations and net hepatic and hindlimb balances of lactate, glycerol, NEFA and Ala

(Mean values with their standard errors, $n 8$ per group)

\begin{tabular}{|c|c|c|c|c|c|c|c|c|c|c|c|c|c|c|c|c|}
\hline \multirow[b]{3}{*}{ Parameters and groups } & & & & & & & & & stprandia & $\mathrm{me}(\min$ & & & & & & \\
\hline & \multicolumn{2}{|c|}{ Basal period } & \multicolumn{2}{|c|}{30} & \multicolumn{2}{|c|}{45} & \multicolumn{2}{|c|}{60} & \multicolumn{2}{|c|}{90} & \multicolumn{2}{|c|}{120} & \multicolumn{2}{|c|}{210} & \multicolumn{2}{|c|}{390} \\
\hline & Mean & SEM & Mean & SEM & Mean & SEM & Mean & SEM & Mean & SEM & Mean & SEM & Mean & SEM & Mean & SEM \\
\hline \multicolumn{17}{|c|}{ Lactate } \\
\hline \multicolumn{17}{|c|}{ Arterial blood lactate $(\mu \mathrm{mol} / \mathrm{l})$} \\
\hline NP & 747 & 112 & 1204 & 104 & 1454 & 156 & 1467 & 123 & 1231 & 120 & 1174 & 143 & 973 & 114 & 797 & 122 \\
\hline $\mathrm{P}$ & 808 & 174 & 1188 & 224 & 1381 & 187 & 1724 & 182 & 1818 & 216 & 1588 & 219 & 1070 & 99 & 885 & 110 \\
\hline \multicolumn{17}{|c|}{$\begin{array}{l}\text { Net hepatic lactate balance } \\
\quad(\mu \mathrm{mol} / 100 \mathrm{~g} \text { liver per } \mathrm{min}) \dagger\end{array}$} \\
\hline NP & $7 \cdot 2$ & $13 \cdot 4$ & $61 \cdot 7$ & $16 \cdot 2$ & $61 \cdot 8$ & 8.8 & 61.5 & 8.6 & 48.6 & $12 \cdot 7$ & $32 \cdot 8$ & $14 \cdot 3$ & $7 \cdot 2$ & $12 \cdot 2$ & $18 \cdot 6$ & $9 \cdot 3$ \\
\hline $\mathrm{P}$ & -0.4 & $9 \cdot 2$ & $31 \cdot 2$ & $16 \cdot 5$ & $49 \cdot 6$ & 14.4 & 48.4 & $10 \cdot 4$ & 39.9 & $12 \cdot 2$ & $18 \cdot 6$ & 8.4 & $-4 \cdot 0$ & 6.6 & 11.7 & $8 \cdot 8$ \\
\hline \multicolumn{17}{|c|}{ Hindlimb lactate balance $(\mu \mathrm{mol} / \mathrm{min}) \dagger$} \\
\hline NP & $-8 \cdot 7$ & $6 \cdot 6$ & -33.9 & $10 \cdot 1$ & $-26 \cdot 3$ & $7 \cdot 4$ & $-33 \cdot 0$ & 6.8 & $-10 \cdot 4$ & $11 \cdot 8$ & $-8 \cdot 8$ & $13 \cdot 3$ & $-11 \cdot 8$ & 8.6 & $5 \cdot 1$ & 4.8 \\
\hline $\mathrm{P}$ & -3.9 & 3.6 & $-9 \cdot 2$ & 13.8 & $-2 \cdot 1$ & $7 \cdot 3$ & -13.7 & $6 \cdot 2$ & $-10 \cdot 9$ & $7 \cdot 1$ & -9.9 & $8 \cdot 1$ & $5 \cdot 1$ & 9.7 & 3.9 & $3 \cdot 1$ \\
\hline \multicolumn{17}{|l|}{ Glycerol } \\
\hline \multicolumn{17}{|c|}{ Arterial blood glycerol $(\mu \mathrm{mol} / \mathrm{l})$} \\
\hline NP & 78 & 15 & 43 & 9 & 34 & 5 & 37 & 2 & 41 & 5 & 48 & 6 & 54 & 5 & 69 & 8 \\
\hline $\mathrm{P}$ & 95 & 8 & 51 & 8 & 46 & 5 & 45 & 3 & 48 & 5 & 54 & 7 & 62 & 7 & 84 & 7 \\
\hline \multicolumn{17}{|c|}{$\begin{array}{l}\text { Net hepatic glycerol uptake } \\
(\mu \mathrm{mol} / 100 \mathrm{~g} \text { liver per min })\end{array}$} \\
\hline NP & $5 \cdot 2$ & 1.4 & $2 \cdot 1$ & 0.4 & $2 \cdot 4$ & 0.8 & $2 \cdot 4$ & 0.4 & $2 \cdot 7$ & 0.3 & 3.8 & 0.8 & 4.0 & 0.5 & $4 \cdot 6$ & 0.7 \\
\hline $\mathrm{P}$ & 4.7 & 0.8 & $2 \cdot 7$ & 0.9 & $2 \cdot 3$ & 0.4 & $2 \cdot 2$ & 0.2 & 1.9 & 0.3 & $2 \cdot 6$ & 0.3 & 2.9 & 0.4 & 3.8 & 0.6 \\
\hline \multicolumn{17}{|c|}{ Hindlimb glycerol release ( $\mu \mathrm{mol} / \mathrm{min})$} \\
\hline NP & 3.5 & 0.9 & $2 \cdot 2$ & 1.7 & 1.6 & 0.5 & 1.6 & 0.7 & $2 \cdot 4$ & 0.7 & 1.6 & 0.5 & 3.8 & 0.8 & $4 \cdot 1$ & 1.5 \\
\hline $\mathrm{P}$ & $1.5^{\star}$ & 0.8 & 0.6 & 1.0 & 0.6 & 0.7 & 0.6 & 0.4 & 0.9 & 0.3 & 0.4 & 0.7 & 1.4 & 0.6 & $1 \cdot 3$ & 2.5 \\
\hline \multicolumn{17}{|c|}{$\begin{array}{l}\text { NEFA } \\
\text { Arterial plasma NEFA ( } \mu \mathrm{mol} / \mathrm{l})\end{array}$} \\
\hline \multicolumn{17}{|c|}{ Arterial plasma NEFA $(\mu \mathrm{mol} / \mathrm{l})$} \\
\hline NP & 755 & 104 & 211 & 30 & 148 & 21 & 150 & 18 & 160 & 28 & 192 & 29 & 221 & 30 & 501 & 50 \\
\hline $\mathrm{P}$ & $972^{*}$ & 138 & $515^{\star}$ & 141 & $398^{*}$ & 105 & $299^{*}$ & 73 & $211^{*}$ & 44 & 223 & 49 & 325 & 104 & 421 & 44 \\
\hline $\begin{array}{l}\text { Net hepatic NEFA upte } \\
(\mu \mathrm{mol} / 100 \mathrm{~g} \text { liver }\end{array}$ & & & & & & & & & & & & & & & & \\
\hline NP & 9.0 & $2 \cdot 1$ & 0.5 & 1.4 & 0.7 & 0.4 & 0.6 & 0.4 & 1.9 & $1 \cdot 2$ & 1.3 & 0.6 & 0.8 & 0.7 & $5 \cdot 1$ & 1.0 \\
\hline $\mathrm{P}$ & $12 \cdot 3$ & 3.0 & $7 \cdot 6^{\star}$ & $2 \cdot 7$ & $7 \cdot 0^{*}$ & $2 \cdot 5$ & $2 \cdot 6$ & 1.4 & 0.3 & 1.8 & 1.7 & 1.5 & 0.8 & 1.6 & $5 \cdot 0$ & 0.9 \\
\hline Hindlimb NEFA uptake & & & & & & & & & & & & & & & & \\
\hline NP & 4.0 & 1.7 & 7.08 & $2 \cdot 2$ & 3.4 & 1.4 & $5 \cdot 0$ & 2.5 & $6 \cdot 7$ & $2 \cdot 4$ & 9.9 & $4 \cdot 0$ & 8.6 & $3 \cdot 2$ & $8 \cdot 4$ & $2 \cdot 6$ \\
\hline $\mathrm{P}$ & $3 \cdot 4$ & $1 \cdot 7$ & 1.9 & $1 \cdot 7$ & 0.3 & $1 \cdot 6$ & 0.6 & $1 \cdot 2$ & $2 \cdot 3$ & $2 \cdot 8$ & $0 \cdot 4^{*}$ & 3.6 & 8.2 & 3.5 & 3.5 & $3 \cdot 2$ \\
\hline Ala & & & & & & & & & & & & & & & & \\
\hline Arterial blood Ala $(\mu \mathrm{mc}$ & & & & & & & & & & & & & & & & \\
\hline NP & 393 & 39 & 511 & 38 & 528 & 29 & 535 & 27 & 498 & 19 & 498 & 24 & 484 & 27 & 518 & 35 \\
\hline $\mathrm{P}$ & $287^{*}$ & 39 & 440 & 66 & 479 & 66 & 542 & 54 & 580 & 41 & 566 & 40 & 519 & 46 & 444 & 44 \\
\hline $\begin{array}{l}\text { Net hepatic Ala uptake } \\
(\mu \mathrm{mol} / 100 \mathrm{~g} \text { liver }\end{array}$ & & & & & & & & & & & & & & & & \\
\hline NP & $8 \cdot 8$ & $1 \cdot 2$ & $19 \cdot 6$ & $1 \cdot 8$ & $25 \cdot 7$ & $6 \cdot 0$ & 21.4 & 1.0 & $25 \cdot 1$ & $2 \cdot 1$ & 29.8 & 2.5 & $27 \cdot 6$ & 3.4 & 8.4 & 1.4 \\
\hline $\mathrm{P}$ & $3 \cdot 6^{*}$ & 1.4 & $7 \cdot 8^{\star}$ & 2.4 & $8 \cdot 5^{\star}$ & $2 \cdot 7$ & $10 \cdot 0$ & 2.9 & $10 \cdot 3$ & 3.6 & $19 \cdot 9$ & 3.4 & $21 \cdot 0$ & 4.7 & 9.4 & 1.7 \\
\hline Hindlimb Ala balance & & & & & & & & & & & & & & & & \\
\hline NP & 0.8 & 0.8 & -0.8 & 1.3 & -0.8 & 1.5 & -1.9 & 1.8 & -1.5 & $1 \cdot 8$ & -0.9 & $5 \cdot 7$ & 0.8 & $3 \cdot 1$ & -2.5 & 4.6 \\
\hline $\mathrm{P}$ & -3.6 & $1 \cdot 2$ & -3.5 & 1.6 & $-4 \cdot 8$ & 3.6 & $-6 \cdot 0$ & 1.3 & -7.6 & 1.5 & $-6 \cdot 3$ & $3 \cdot 3$ & -3.4 & 3.5 & $-1 \cdot 4$ & $8 \cdot 1$ \\
\hline
\end{tabular}

NP, non-pregnant; $P$, pregnant.

* Mean values were significantly different between the groups $(P<0.05$; post hoc analysis).

$\dagger$ Negative rates indicate net uptake. 
Table 3. Maternal glycogen $\ddagger$

(Mean values with their standard errors, $n 8$ per group)

\begin{tabular}{|c|c|c|c|c|c|c|c|c|c|c|c|c|c|c|}
\hline \multirow[b]{4}{*}{ Groups } & \multicolumn{4}{|c|}{ Skeletal muscle } & \multicolumn{10}{|c|}{ Liver } \\
\hline & \multirow{2}{*}{\multicolumn{2}{|c|}{ 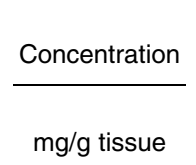 }} & \multirow{2}{*}{\multicolumn{2}{|c|}{$\begin{array}{c}\text { Net synthesis } \\
\mathrm{mg} / \mathrm{g} \text { tissue }\end{array}$}} & \multicolumn{4}{|c|}{ Concentration } & \multicolumn{4}{|c|}{ Net synthesis } & \multicolumn{2}{|c|}{$\begin{array}{c}\text { Direct pathway } \\
\text { contribution }\end{array}$} \\
\hline & & & & & \multicolumn{2}{|c|}{$\begin{array}{l}\mathrm{mg} / 100 \mathrm{~g} \\
\text { tissue }\end{array}$} & \multicolumn{2}{|c|}{ g/liver } & \multicolumn{2}{|c|}{$\mathrm{g} / 100 \mathrm{~g}$ tissue } & \multicolumn{2}{|c|}{ g/liver } & \multicolumn{2}{|c|}{$\%$} \\
\hline & Mean & SEM & Mean & SEM & Mean & SEM & Mean & SEM & Mean & SEM & Mean & SEM & Mean & SEM \\
\hline NP & 9.6 & 0.6 & 1.0 & 0.1 & $5 \cdot 3$ & 0.5 & 38.2 & 4.6 & 0.4 & 0.5 & 3.2 & 4.0 & 48 & 3 \\
\hline $\mathrm{P}$ & $7 \cdot 0^{*}$ & 0.6 & 1.2 & 0.2 & $6 \cdot 1$ & 0.7 & 54.0 & 9.8 & $2 \cdot 6^{*}$ & 0.7 & 23.4 & $7.8 \dagger$ & 50 & 3 \\
\hline
\end{tabular}

NP, non-pregnant; $P$, pregnant.

Mean values were significantly different from those of the NP group: ${ }^{*} P<0.01 ; \dagger P<0.05$.

$\ddagger$ Glycogen concentrations are from biopsies taken at the end of the study. Skeletal muscle concentrations are the mean of concentrations in three muscles (sartorius, gracilis and gastrocnemius), and hepatic concentrations are the weighted (for the percentage contribution of each lobe to total liver mass) mean of seven liver lobes.

and hindlimb blood flow tended to be lower in $\mathrm{P}$ dogs than in NP dogs. In previous studies, we have observed that total hepatic blood flow has been both higher ${ }^{(12,26)}$ and lower ${ }^{(5,31)}$ in $\mathrm{P}$ dogs than in NP controls, when total flow per animal is considered, but it has generally tended to be lower in $\mathrm{P} v$. NP animals when expressed per $100 \mathrm{~g}$ of maternal liver ${ }^{(12)}$. Hindlimb flow has also shown a tendency to be lower during pregnancy ${ }^{(5)}$. In numerous investigations, ultrasonic flow probes have yielded results comparable with those with an independent technique, indocyanine green extraction, both in $\mathrm{P}$ and $\mathrm{NP}$ dogs ${ }^{(5,31,32)}$. Indocyanine green was not infused in the current studies because the postprandial lipaemia renders its measurement virtually impossible. However, we are confident, based on our previous comparisons, that the tendency towards lower blood flows in the $\mathrm{P}$ group did not arise from systematic underestimation by the flow probes. Near term, the uterus and products of conception account for a greater percentage of total body weight in dogs than in humans, and canine uteroplacental flow increases progressively from early to late pregnancy ${ }^{(33)}$. Thus, the most likely explanation for the tendency towards lower hindlimb and hepatic blood flow in the $\mathrm{P}$ group, in comparison with the $\mathrm{N}$ group, is that a large percentage of maternal cardiac output is required for perfusion of the uteroplacental vessels with a concomitant relative decrease in flow to some maternal tissues. A decrease in the proportion of total blood flow directed to the liver is supported by studies in normal $\mathrm{P}$ women ${ }^{(34)}$. Data regarding changes in hepatic blood flow in human pregnancy are conflicting, however. Studies with dye extraction indicate no change in the rate of hepatic blood flow in women during normal pregnancy ${ }^{(34)}$. In contrast, ultrasonography indicates that portal vein blood flow is increased in women during the late second and third trimesters ${ }^{(35,36)}$. The maximal velocity of portal vein flow actually decreases progressively during human pregnancy ${ }^{(37)}$, but an increase in vessel diameter has been reported by one group ${ }^{(35)}$, explaining how portal vein flow could increase. Both portal vein blood flow and diameter have been found to be highly dependent on body position in $\mathrm{P}$ women ${ }^{(35)}$, which may explain some of the disparity in results.
Post-study hepatic glycogen concentrations did not differ between NP and P dogs, which are consistent with the data from rats in the fed state ${ }^{(38)}$. Total net hepatic glycogen synthesis in the P group was 6- to 7-fold higher than in the NP group, however. The calculated net hepatic glycogen synthesis is an underestimate of the actual value in both groups, because the biopsies in the fasted groups were taken after an $18 \mathrm{~h}$ fast, the time at which mixed meal feeding was administered in the study groups. If the fasting biopsies had been taken at the same time as those in the meal-fed animals, the fasting period would have been $24.5 \mathrm{~h}$, and the hepatic glycogen content would have been further reduced since canine hepatic glycogen levels are on a steep portion of the depletion curve during $18-24 \mathrm{~h}$ of fasting ${ }^{(10,39)}$. Moreover, it is probable that the hepatic glycogen levels in $\mathrm{P}$ dogs would have declined more rapidly than those in NP animals, since basal HGP in both dogs and human subjects is greater during late pregnancy than in the NP state ${ }^{(1,12)}$, with glycogenolysis accounting for a substantial portion of basal HGP ${ }^{(12,26)}$. The relatively depleted state of basal hepatic glycogen levels in $\mathrm{P}$ dogs might have contributed to the rapid rate of hepatic glycogen synthesis in the $\mathrm{P}$ group following meal feeding, since greater hepatic glycogen depletion achieved by longer fasting (i.e. $42 v, 18 \mathrm{~h}$ ) is known to be associated with a more rapid rate of hepatic glycogen synthesis during duodenal glucose infusion in normal dogs ${ }^{(40)}$. Additionally, both oestradiol and progesterone, hormones that are elevated more than 2-fold during late pregnancy compared with anoestrus ${ }^{(41)}$, stimulate hepatic glycogen synthesis in rats and mice ${ }^{(42-44)}$. The percentage contribution of the direct and indirect pathways did not differ between the NP and P groups, indicating that the rate of synthesis via both pathways was stimulated in $\mathrm{P}$ dogs. The enhancement of glycogen synthase activity stimulated by the increase in postprandial hepatic glucose 6-phosphate probably resulted in both glucose and gluconeogenic substrates being directed towards glycogen synthesis. Consistent with this, postprandial net hepatic lactate output tended to be reduced in the $\mathrm{P}$ group, indicating that glycolytic carbon was directed towards glycogen synthesis rather than hepatic release. The marked enhancement of 
postprandial hepatic glycogen synthesis is likely to be a significant contributor to the maintenance of glucose homeostasis in pregnancy, replenishing the stores needed to maintain a constant source of glucose for fetal and maternal metabolism.

Under hyperinsulinaemic euglycaemic clamp conditions, hindlimb glucose uptake is reduced approximately $33 \%$ in dogs during late pregnancy ${ }^{(5)}$, providing clear evidence of peripheral insulin resistance. Nevertheless, the insulin response to the mixed meal was not enhanced in the $\mathrm{P}$ group, in keeping with our previous finding that the canine $\beta$-cell exhibits no apparent adaptation (hypertrophy, hyperplasia or neogenesis) during pregnancy ${ }^{(16)}$. In spite of the insulin resistance of pregnancy and the lack of compensatory insulin secretion, the $\mathrm{P}$ group's postprandial hindlimb glucose uptake was unimpaired. Postprandial hyperglycaemia apparently allowed $\mathrm{P}$ dogs to overcome the pregnancy-associated peripheral insulin resistance in order to maintain rates of hindlimb glucose uptake indistinguishable from those in the NP group, because adjustment of the glucose uptake rates for the load of inflowing glucose demonstrated that the AUC of fractional glucose extraction by the hindlimb was markedly lower in $\mathrm{P} v$. NP dogs. Muscle glycogen synthetic rates were at least as rapid in $\mathrm{P}$ dogs as in NP dogs, but the muscle glycogen concentrations were significantly lower in the $\mathrm{P}$ $v$. NP group at the end of the study. Hindlimb glucose oxidation was similar in the two groups, consistent with lower basal muscle glycogen concentrations and/or greater rates of peripheral lipid accumulation in pregnancy.

The glucagon response to hypoglycaemia is markedly blunted during late pregnancy in the normal human subjects, rats and $\operatorname{dogs}(26,32,45,46)$. The increase in the hormone in response to mixed meal feeding was indistinguishable in the NP and P groups; however, demonstrating that there is no inherent defect in glucagon secretion during pregnancy. Thus, the impairment of the counter regulatory glucagon response in late pregnancy is likely to be related to a specific defect in the sensing or response to hypoglycaemia, as we have suggested previously ${ }^{(32)}$.

In the basal period, $\mathrm{P}$ dogs exhibited no net hepatic lactate output, and their arterial NEFA concentrations were higher and glycerol concentrations tended to be higher than those in NP dogs. Similarly, hepatic ketone release tended to be elevated in the $\mathrm{P}$ animals. All of these findings reflect a longer fasted condition ${ }^{(47)}$, in keeping with the description of pregnancy as a state of accelerated starvation ${ }^{(24)}$. Circulating glycerol concentrations (a sensitive indicator of lipolysis) declined to similar levels in both groups after the meal, demonstrating that suppression of lipolysis under postprandial conditions remained intact in $\mathrm{P}$ dogs.

The classic hyperinsulinaemic euglycaemic clamp technique has been described as the gold standard for examining insulin sensitivity ${ }^{(48)}$, but it has a limited ability to assess the full dynamic range of liver glucose disposal, which includes both suppression of HGP and enhancement of HGU. Glucose disposal in response to enteral intake of glucose or a mixed meal is a function of the interaction of numerous factors, including insulin and glucagon secretion, peripheral insulin sensitivity, the degree of suppression of
HGP, and the rate of $\mathrm{HGU}^{(48)}$. The portal signal generated by enteral glucose delivery serves both to enhance liver glucose uptake and suppress muscle glucose uptake ${ }^{(20)}$. Indices derived from the oral glucose tolerance test can serve as estimates of both muscle and liver insulin sensitivity and have been determined to be highly predictive of the development of type 2 diabetes $^{(49)}$. Thus, glucose ${ }^{(49,50)}$ or mixed meal ${ }^{(7)}$ ingestion provides a useful physiological tool for assessing glucose disposal.

In conclusion, pregnancy was associated with postprandial hyperglycaemia following mixed meal feeding, but hepatic and hindlimb glucose uptake was unimpaired compared with the NP state. The liver in $\mathrm{P}$ dogs played a very active role in glucose metabolism, with the hepatic glycogen synthetic rate (net mass of glycogen deposited over the postprandial time period) and glucose oxidation being significantly greater in the $\mathrm{P} v$. NP group. The avid nature of postprandial hepatic glycogen synthesis in the $\mathrm{P}$ animals probably ensures the maintenance of adequate maternal glucose concentrations to allow an uninterrupted supply of glucose to the products of conception. The potential for use of a mixed meal rather than an oral glucose load to assess glucose metabolism in pregnancy deserves further examination, since it can elicit information not only about glucose tolerance but also about other aspects of postprandial metabolism.

\section{Acknowledgements}

The present study was supported by NIH DK 058134, Juvenile Diabetes Foundation International Research grant 193113 (C. C. C.), and American Diabetes Association Research Award 7-06-RA-96 (M. C. M.). The Hormone Assay \& Analytical Services Core and the Metabolic Physiology Shared Resource Core of the Vanderbilt Diabetes Research and Training Center, supported by NIDDK grant DK-20593, made substantial contributions to the study. The authors have no conflicts of interest. M. C. M. participated in designing the experiments and was responsible for the analysis and interpretation of the data and preparation of the manuscript. M. S. S. collected and analysed the data. C. C. C. participated in designing these experiments, obtained funding for them, and participated in the collection, analysis and interpretation of the data.

\section{References}

1. Catalano PM, Tyzbir ED, Wolfe RR, et al. (1992) Longitudinal changes in basal hepatic glucose production and suppression during insulin infusion in normal pregnant women. Am J Obstet Gynecol 167, 913-919.

2. Girard J, Burnol AF, Leturque A, et al. (1987) Glucose homoeostasis in pregnancy and lactation. Biochem Soc Trans 15, 1028-1030.

3. Gilbert M, Pere MC, Baudelin A, et al. (1991) Role of free fatty acids in hepatic insulin resistance during late pregnancy in conscious rabbits. Am J Physiol 260, E938-E945.

4. Butte NF (2000) Carbohydrate and lipid metabolism in pregnancy: normal compared with gestational diabetes mellitus. Am J Clin Nutr 71, 1256S-1261S. 
5. Connolly CC, Papa T, Smith MS, et al. (2007) Hepatic and muscle insulin action during late pregnancy in the dog. Am J Physiol Regul Integr Comp Physiol 292, $\mathrm{R} 447-\mathrm{R} 452$.

6. Lain KY \& Catalano PM (2007) Metabolic changes in pregnancy. Clin Obstet Gynecol 50, 938-948.

7. Maki KC, Rains TM, Dicklin MR, et al. (2010) Repeatability of indices of insulin sensitivity and secretion from standard liquid meal tests in subjects with type 2 diabetes mellitus or normal or impaired fasting glucose. Diabetes Technol Ther 12, 895-900.

8. Owens DR, Wragg KG, Biggs PI, et al. (1981) The reproducibility of serial meal and oral glucose tolerance tests in normal subjects. Diabete Metab 7, 25-33.

9. Wolever TM, Chiasson JL, Csima A, et al. (1998) Variation of postprandial plasma glucose, palatability, and symptoms associated with a standardized mixed test meal versus $75 \mathrm{~g}$ oral glucose. Diabetes Care 21, 336-340.

10. Moore MC, Pagliassotti MJ, Swift LL, et al. (1994) Disposition of a mixed meal by the conscious dog. Am J Physiol 266, E666-E675.

11. Wasserman DH, Lacy DB, Bracy D, et al. (1992) Metabolic regulation in peripheral tissues and transition to increased gluconeogenic mode during prolonged exercise. $A m J$ Physiol 263, E345-E354.

12. Connolly CC, Holste LC, Aglione LN, et al. (2000) Alterations in basal glucose metabolism during late pregnancy in the conscious dog. Am J Physiol Endocrinol Metab 279, E1166-E1177.

13. Pagliassotti MJ, Holste LC, Moore MC, et al. (1996) Comparison of the time courses of insulin and the portal signal on hepatic glucose and glycogen metabolism in the conscious dog. J Clin Invest 97, 81-91.

14. Shiota M, Golden S \& Katz J (1984) Lactate metabolism in the perfused rat hindlimb. Biochem J 222, 281-292.

15. Keppler D \& Decker K (1974) Glycogen: determination with amyloglucosidase. In Methods of Enzymatic Analysis, pp. 1127-1131 [HU Bergmeyer, editor]. New York: Verlag Chemic Weinheim, Academic Press.

16. Moore MC, Menon R, Coate KC, et al. (2011) Diet-induced impaired glucose tolerance and gestational diabetes in the dog. J Appl Physiol 110, 458-467.

17. Liu CY, Chen LB, Liu PY, et al. (2002) Effects of progesterone on gastric emptying and intestinal transit in male rats. World J Gastroenterol 8, 338-341.

18. Jones KL, Berry M, Kong MF, et al. (1999) Hyperglycemia attenuates the gastrokinetic effect of erythromycin and affects the perception of postprandial hunger in normal subjects. Diabetes Care 22, 339-344.

19. Kuo P, Gentilcore D, Nair N, et al. (2009) The nitric oxide synthase inhibitor, $n^{\mathrm{g}}$-nitro-L-arginine-methyl-ester, attenuates the delay in gastric emptying induced by hyperglycaemia in healthy humans. Neurogastroenterol Motil $\mathbf{2 1}$ 1175-e103

20. Cherrington AD (1999) Banting lecture 1997. Control of glucose uptake and release by the liver in vivo. Diabetes 48, 1198-1214.

21. Pere MC, Baudelin A, Briggs K, et al. (1992) Hepatic metabolism during fasting-refeeding transition in conscious pregnant rabbits. Am J Physiol 262, E899-E905.

22. Hauguel S, Gilbert M \& Girard J (1987) Pregnancy-induced insulin resistance in liver and skeletal muscles of the conscious rabbit. Am J Physiol 252, E165-E169.

23. Catalano PM, Nizielski SE, Shao J, et al. (2002) Downregulated IRS-1 and PPARgamma in obese women with gestational diabetes: relationship to FFA during pregnancy. Am J Physiol Endocrinol Metab 282, E522-E533.

24. Metzger BE, Ravnikar V, Vileisis RA, et al. (1982) "Accelerated starvation" and the skipped breakfast in late normal pregnancy. Lancet 1, 588-592.

25. Sivan E, Homko CJ, Chen X, et al. (1999) Effect of insulin on fat metabolism during and after normal pregnancy. Diabetes 48, 834-838.

26. Connolly CC, Aglione LN, Smith MS, et al. (2004) Pregnancy impairs the counterregulatory response to insulin-induced hypoglycemia in the dog. Am J Physiol Endocrinol Metab 287, E480-E488.

27. Sivan E, Homko CJ, Whittaker PG, et al. (1998) Free fatty acids and insulin resistance during pregnancy. $J$ Clin Endocrinol Metab 83, 2338-2342.

28. Cherrington AD, Edgerton D \& Sindelar DK (1998) The direct and indirect effects of insulin on hepatic glucose production in vivo. Diabetologia 41, 987-996.

29. Moore MC, Smith MS, Lacy DB, et al. (2008) The liver's response to hyperglycemia is delayed in late pregnancy. Diabetes 57, A512.

30. Blanco PG, Tórtora M, Rodríguez R, et al. (2010) Ultrasonographic assessment of maternal cardiac function and peripheral circulation during normal gestation in dogs. Vet $J$ (epublication ahead of print version 11 october 2010).

31. Connolly CC, Aglione LN, Smith MS, et al. (2004) Insulin action during late pregnancy in the conscious dog. $A m \mathrm{~J}$ Physiol Endocrinol Metab 286, E909-E915.

32. Canniff KM, Smith MS, Lacy DB, et al. (2006) Glucagon secretion and autonomic signaling during hypoglycemia in late pregnancy. Am J Physiol Regul Integr Comp Physiol 291, R788-R795.

33. Nautrup CP (1998) Doppler ultrasonography of canine maternal and fetal arteries during normal gestation. J Reprod Fertil 112, 301-314.

34. Munnell EW \& Taylor HC (1947) Liver blood flow in pregnancy - hepatic vein catheterization. J Clin Invest 26, 952-956.

35. Clapp JF 3rd, Stepanchak W, Tomaselli J, et al. (2000) Portal vein blood flow - effects of pregnancy, gravity, and exercise. Am J Obstet Gynecol 183, 167-172.

36. Nakai A, Sekiya I, Oya A, et al. (2002) Assessment of the hepatic arterial and portal venous blood flows during pregnancy with Doppler ultrasonography. Arch Gynecol Obstet 266, 25-29.

37. Bozgeyik Z, Ozdemir H, Kocakoc E, et al. (2009) Hepatic and portal venous Doppler waveforms and flow velocities in normal pregnancy. Med Sci Monit 15, CR624-CR627.

38. Herrera E, Knopp RH \& Freinkel N (1969) Carbohydrate metabolism in pregnancy. VI. Plasma fuels, insulin, liver composition, gluconeogenesis, and nitrogen metabolism during late gestation in the fed and fasted rat. J Clin Invest 48, 2260-2272.

39. Hendrick GK, Frizzell RT, Williams PE, et al. (1990) Effect of hyperglucagonemia on hepatic glycogenolysis and gluconeogenesis after a prolonged fast. Am J Physiol 258, E841-E849.

40. Galassetti P, Hamilton KS, Gibbons FK, et al. (1999) Effect of fast duration on disposition of an intraduodenal glucose load in the conscious dog. Am J Physiol 276, E543-E552.

41. Concannon PW, McCann JP \& Temple M (1989) Biology and endocrinology of ovulation, pregnancy and parturition in the dog. Journal Reprod Fert Suppl 39, 3-25. 
42. Carrington LJ \& Bailey CJ (1985) Effects of natural and synthetic estrogens and progestins on glycogen deposition in female mice. Horm Res 21, 199-203.

43. Mohla S \& Prasad MR (1968) Inhibition of estrogen induced glycogen synthesis in the rat by clomiphene. Steroids 11, 571-583.

44. Kalkhoff RK (1982) Metabolic effects of progesterone. Am J Obstet Gynecol 142, 735-738.

45. Rossi G, Lapaczewski P, Diamond MP, et al. (1993) Inhibitory effect of pregnancy on counterregulatory hormone responses to hypoglycemia in awake rat. Diabetes $\mathbf{4 2}, 1440-1445$.

46. Rosenn BM, Miodovnik M, Khoury JC, et al. (1996) Counterregulatory hormonal responses to hypoglycemia during pregnancy. Obstet Gynecol 87, 568-574.
47. Moore MC, Pagliassotti MJ, Wasserman DH, et al. (1993) Hepatic denervation alters the transition from the fed to the food-deprived state in conscious dogs. J Nutr 23, 1739-1746.

48. Defronzo RA (2009) Banting lecture. From the triumvirate to the ominous octet: a new paradigm for the treatment of type 2 diabetes mellitus. Diabetes 58, 773-795.

49. Abdul-Ghani MA, Matsuda M, Balas B, et al. (2007) Muscle and liver insulin resistance indexes derived from the oral glucose tolerance test. Diabetes Care 30, 89-94.

50. Abdul-Ghani MA, Williams K, DeFronzo RA, et al. (2007) What is the best predictor of future type 2 diabetes? Diabetes Care 30, 1544-1548. 